\title{
An Exploratory Study of Tridentate Amine Extractants: Solvent Extraction and Coordination Chemistry of Base Metals with Bis((1R-benzimidazol-2-yl)methyl)amine
}

\author{
Nomampondo P. Magwa ${ }^{1}$, Eric Hosten ${ }^{2}$, Gareth M. Watkins ${ }^{1}$, Zenixole R. Tshentu ${ }^{{ }^{*}}$ \\ ${ }^{1}$ Department of Chemistry, Rhodes University, Grahamstown, South Africa \\ ${ }^{2}$ Department of Chemistry, Nelson Mandela Metropolitan University, Port Elizabeth, South Africa \\ Email: z.tshentu@ru.ac.za
}

Received July 19, 2012; revised August 25, 2012; accepted September 12, 2012

\begin{abstract}
Solvent extraction of base metals using bis((1-decylbenzimidazol-2-yl)methyl)amine (BDNNN) showed a lack of $\mathrm{pH}$-metric separation of the metals. The extraction system was described quantitatively using the equilibria involved to derive the mathematical explanation for the two linear $\log \mathrm{D} v \mathrm{vs} \mathrm{H}_{\mathrm{e}}$ plots for each metal ion extraction curve, and coordination numbers could also be extracted from the two slopes. The lack of separation was attributed to the absence of stereochemical "tailor making" since the complexes isolated from the reaction of the ligand, bis $($ (1H-benzimidazol2-yl)methyl)amine (NNN), with base metals suggested the formation of similar octahedral complex species from spectral and crystal structure evidence. The bis tridentate coordination observed was in agreement with information extracted from the extraction data. This investigation opens up an opportunity and an approach for the evaluation of amines as extractants but cautions against tridentate ligands.
\end{abstract}

Keywords: Base Metals; Tridentate; Bis((1H-benzimidazol-2-yl)methyl)amine; Extractive and Coordination Chemistry

\section{Introduction}

There is an increasing demand for substantial production of metals of high purity in the metallurgical industries in an attempt to meet the corresponding demand for both industrial and domestic applications. This has been the catalyst for the development of simpler and more economical routes for purification of metal ions from their ore solutions. The scale for example of nickel operations is limited, and therefore one has to maximise profit via processing efficiency rather than volume. The ultimate goal is to design processes that are environmentally friendly, cost-effective, time-saving and selective. Solvent extraction, a widely applied technique for the recovery of base metals $[1,2]$, meets some of these principles since high boiling point and high flashpoint solvents are used and are recycled together with an extractant after the stripping step, and the system can be tuned through appropriate extractant design to achieve selectivity [3]. The basis of base metal ion separation is a unique property of the coordination chemistry of the particular metal ion. In the development of a metal ion specific extractant, it is necessary to consider the charac-

${ }^{*}$ Corresponding author. teristics of the metal ions from which the desired metal ion must be removed as well as its own [3]. Improvements of the chemical processes in the solvent extraction system require a thorough knowledge and investigation of the chemistry involved in order to achieve a meaningful advancement of this technology.

There has been an envisaged shift towards aminebased extractants, and this is motivated by the favourable properties that are offered by the nitrogenous ligands especially the aromatic amines as compared with oxygenbased extractants [3-5]. Some of these properties include the intermediate $\mathrm{p} K_{\mathrm{a}}$ values as well as $\sigma$ and $\pi$ bonding capabilities resulting in extractions in the low $\mathrm{pH}$ range and in a possibility of separation through bonding preferences respectively. The latter property has been dubbed "stereochemical tailor-making" by du Preez [5]. On the other hand, the strong aliphatic amine ligands with $\sigma$ donor only character show lack of relative preference for the metal ions but this can be improved if chelates are used, and also tend to form metal complexes at relatively high $\mathrm{pH}$ values which is undesirable [5]. The chelate effect has also been exploited effectively in a bidentate aromatic system (1-octyl-2,2'-pyridylimidazole) providing for effective separation of nickel from other base 
metals in strong acidic sulfate solutions with a possibility of back-extraction [3].

An extension of these systems to tridentate ligands would have an additional advantage of increasing the extraction equilibrium constants [6] due to the high complex formation constants for reactions of base metals and tridentate ligands $[7,8]$, thereby requiring relatively low extractant-to-metal ratios to achieve quantitative extractions [6]. The only example of a tridentate amine extractant in the literature is that of a derivative of diethylenetriamine [9] but extractions occurred at relatively high $\mathrm{pH}$ values as expected due to high $\mathrm{p} K_{\mathrm{a}}$ values of aliphatic amines [8], and the small $\Delta \mathrm{pH}_{0.5}$ values implied a lack of $\mathrm{pH}$-metric separation of the later $3 \mathrm{~d}$ metal ions [9]. It would be hoped that good separation factors of the metal chelates would be achieved through stereochemical considerations since nickel(II) is known to form the most stable spin free octahedral $\left(\mathrm{O}_{\mathrm{h}}\right)$ complexes of all base metal ions [10] while the copper(II) and cobalt(II) ions tend to form stable tetrahedral $\left(\mathrm{T}_{\mathrm{d}}\right)$ complexes $[4,11]$. This study, therefore, also interrogates the coordination chemistry aspects of base metals, that infuence the extractions, with tridentate amine-based ligands.

In this account, we present the extractive and coordination chemistry of an aromatic tridentate ligand, bis((1H-benzimidazol-2-yl)methyl)amine (NNN) (Figure 1(a)), towards base metals in a sulfate/sulfonate medium. Dinonylnaphthalene sulfonic acid (DNNSA) (Figure 1(b)) was used as a bulky anion to ion-pair and transfer the cationic complexes formed in this extraction system (ion-association system) to the organic phase since the sulfate ion is known to have high hydration energies leading to lack of phase transferability [12]. The sulfate medium has become particularly important to explore since it is encountered in liquors produced in sulfatebased high nickel matte leach processes or those produced in sulfuric acid pressure leaching of laterites [13].

\section{Experimental}

\subsection{Materials}

$o$-Phenylenediamine (99.5\%, Sigma-Aldrich), iminodiacetic acid (98\%, Sigma-Aldrich), hydrochloric acid

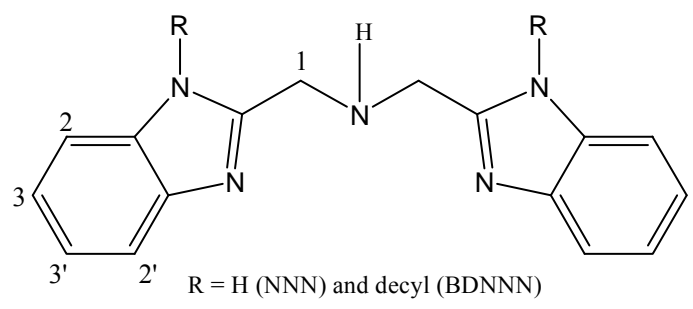

(a)
(32\%, Merck Chemicals), ammonia (28\%, Merck Chemicals), methanol (99\%, Sigma-Aldrich), and ethyl acetate (98\%, Sigma-Aldrich) were reagent grade chemicals used as received for the synthesis of bis $((1 H$-benzimidazol2-yl)methyl)amine (NNN). The reagent grade octylbromide (98\%) was also obtained from Sigma-Aldrich and used as received for the synthesis of the extractant. $\mathrm{NiSO}_{4} \cdot 6 \mathrm{H}_{2} \mathrm{O}(98 \%), \mathrm{CuSO}_{4} \cdot 5 \mathrm{H}_{2} \mathrm{O}(99 \%)$ were obtained from Merck chemicals. $\mathrm{CoSO}_{4} \cdot 7 \mathrm{H}_{2} \mathrm{O}(97.5 \%)$ was obtained from Fluka, while $\mathrm{ZnSO}_{4} \cdot 7 \mathrm{H}_{2} \mathrm{O}(99.5 \%)$ was obtained from BDH Chemicals. The copper(II), nickel(II), cobalt(II) and zinc(II) perchlorate hexahydrate salts which were used to prepare the metal(II) sulfonate salts using toluene-4-sulfonic acid (98\%, Sigma-Aldrich) were obtained from Sigma-Aldrich. Analytical grade reagents were used without further purification in the preparations of the $0.10 \mathrm{M}$ metal ion stock solutions in $3 \mathrm{M} \mathrm{H}_{2} \mathrm{SO}_{4}$ solution. The ICP/AAS 1000 ppm metal standards, dissolved in $0.5 \mathrm{~N}$ nitric acid, were used to prepare standard solutions for the construction of calibration curves using distilled, deionized, milliQ water for the dilutions. Dinonylnaphthalene sulfonic acid (50 wt $\%$ in heptane), Shellsol 2325 (17 - $22 \mathrm{v} / \mathrm{v} \%$ aromatic content) and 2-octanol (98\%) were obtained from Sigma-Aldrich, Shell Chemicals (SA) and Merck Chemicals, respectively.

\subsection{Instrumentation}

${ }^{1} \mathrm{H}$ NMR spectrometry was carried out on a Bruker AMX $400 \mathrm{MHz}$ NMR spectrometer and reported relative to tetramethylsilane $(\delta$ 0.00). A Vario Elementary ELIII Microcube CHNS analyser was used for elemental analyses. A Thermo Electron (iCAP 6000 Series) inductively coupled plasma (ICP) spectrometer equipped with an OES detector was used for metal ion analysis. The Labcon micro-processor controlled orbital platform shaker model SPO-MP 15 was used for contacting the two phases of extraction. The $\mathrm{pH}$ measurements were performed on a Metrohm $827 \mathrm{pH}$ meter using a combination electrode with $3 \mathrm{M} \mathrm{KCl}$ as electrolyte. The metalcomplexes were characterised using infrared spectrome try on both Perkin Elmer 400 FTIR and 100 FTIR-ATR

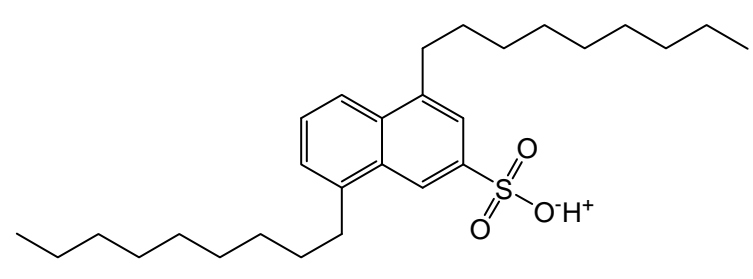

(b)

Figure 1. The chemical structures of (a) bis((1R-benzimidazol-2-yl)methyl)amine (NNN for $R=H$, and BDNNN for $R=$ Decyl) and (b) dinonylnaphthalene sulfonic acid (DNNSA). 
spectrometers. The solid reflectance spectra of the metal complexes were recorded on a Shimadzu UV-VIS-NIR Spectrophotometer UV-3100 with a MPCF-3100 sample compartment with samples mounted between two quartz discs which fit into a sample holder coated with barium sulfate. The spectra were recorded over the wavelength range of $2000-250 \mathrm{~nm}$, and the scans were conducted at a medium speed using a $20 \mathrm{~nm}$ slit width. The Gallenkamp melting point apparatus (temperature range, $0^{\circ} \mathrm{C}$ $350^{\circ} \mathrm{C}$ ) was used to measure the melting points. The conductivity measurements were carried out on a A.W.R. Smith Process Instrumentation cc Laboratory Bench Meter Model AZ 86555 with ABS graphite cell probe using an aqueous standard which has a conductivity value of $135 \mathrm{ohm}^{-1} \cdot \mathrm{cm}^{2} \cdot \mathrm{mole}^{-1}$ at $20^{\circ} \mathrm{C}$ for the calibration. All the complexes were prepared in DMF as a solvent to a concentration of $10^{-3} \mathrm{M}$ for the conductivity measurements.

\subsection{Synthesis of the Ligand and Extractant}

\subsubsection{Bis((1H-benzimidazol-2-yl)methyl)amine (NNN)}

The bis((1H-benzimidazol-2-yl)methyl)amine (NNN) was synthesized as reported elsewhere [14], except that iminodiacetic acid was used and the decolorization step using activated charcoal in methanol was necessary. The characterization data for the white precipitate of the free base was as follows: Yield: $84 \%$, m.p., $268^{\circ} \mathrm{C}-270^{\circ} \mathrm{C}$. Anal. Calcd. for $\mathrm{C}_{16} \mathrm{H}_{16} \mathrm{~N}_{4} \mathrm{OS}(\%)$ : C, 65.10; H, 5.80; N, 23.70. Found: C, 65.78; H, 5.80; N, 23.07. ${ }^{1} \mathrm{H} \cdot \mathrm{NMR}$ $\left(\mathrm{CDCl}_{3}\right) \delta(\mathrm{ppm}): 4.06(4 \mathrm{H}, \mathrm{s}, H 1), 7.15\left(4 \mathrm{H}, \mathrm{m}, H 3, H 3^{\prime}\right)$, $7.52\left(4 \mathrm{H}, \mathrm{m}, H 2, H 2^{\prime}\right)$. IR $\left(\mathrm{cm}^{-1}\right): 3208 v(\mathrm{~N}-\mathrm{H}), 3049$ $v(\sec \mathrm{N}-\mathrm{H}), 1592 v(\mathrm{C}=\mathrm{N})$.

\subsubsection{Bis((1-decylbenzimidazol-2-yl)methyl)amine (BDNNN)}

The alkylated derivative of the ligand was prepared according to a literature method [15]. However, the purifycation step was carried out as follows: The resulting solution after the removal of the $\mathrm{KBr}$ salt was concentrated via rotary evaporation, and purified using a silica gel chromatographic column with ethyl acetate/methanol (4:1) solvent system. After the removal of the solvent by rotary evaporation the product was obtained as brown oil. Yield $=67 \%$. Anal. Calcd. for $\mathrm{C}_{36} \mathrm{H}_{59} \mathrm{~N}_{5} \mathrm{O}_{2}(\%)$ : C, 72.81; H, 10.01; N, 11.79. Found: C, 72.95; H, 10.61; N, 11.86 . ${ }^{1} \mathrm{H}$ NMR $\left(\mathrm{CDCl}_{3}\right) \delta(\mathrm{ppm}): \delta 0.89\left(6 \mathrm{H}, \mathrm{t}, \mathrm{CH}_{3}\right), 1.13$ $\left(24 \mathrm{H}, \mathrm{m}, \mathrm{CH}_{3}\left(\mathrm{CH}_{2}\right)_{6}\right), 1.01\left(4 \mathrm{H}, \mathrm{t}, \mathrm{CH}_{2}-\mathrm{CH}_{3}\right), 1.55(4 \mathrm{H}, \mathrm{t}$, $\left.\mathrm{CH}_{2}-\mathrm{CH}_{2} \mathrm{~N}\right), 3.96\left(4 \mathrm{H}, \mathrm{t}, \mathrm{CH}_{2}-\mathrm{N}\right), 4.02(4 \mathrm{H}, \mathrm{s}, \mathrm{H1}), 7.26$ $\left(4 \mathrm{H}, \mathrm{q}, H 3 \& H 3^{\prime}\right), 7.28(2 \mathrm{H}, \mathrm{d}, H 2), 7.75\left(2 \mathrm{H}, \mathrm{d}, H 2^{\prime}\right)$. IR $\left(\mathrm{cm}^{-1}\right): 1522 \mathrm{v}(\mathrm{C}=\mathrm{N})$.

\subsection{Syntheses of Metal Complexes}

All the reactions for the formation of coordination complexes (sulfonate and sulfate compounds) were con- ducted in absolute ethanol using the toluene-4-sulfonate salts of the metals, and inert conditions were adopted for the synthesis. $10 \mathrm{~mL}$ of hot ethanolic solution $\left(60^{\circ} \mathrm{C}\right)$ containing $2 \mathrm{mmol}$ of the ligand was added dropwise to $10 \mathrm{~mL}$ of the metal ion solution $(1 \mathrm{mmol}$, respectively for each metal ion). The mixture was heated under reflux overnight and the precipitate that formed was filtered off, washed with ethanol and dried.

\subsubsection{Sulfate Complexes}

$\left[\mathrm{Co}(\mathrm{NNN})_{2}\right] \mathrm{SO}_{4} \cdot 4 \mathrm{H}_{2} \mathrm{O}$ : Color: pink. Yield $=51 \%$, m.p., $252^{\circ} \mathrm{C}-254^{\circ} \mathrm{C}$. Anal. Calcd. for $\mathrm{C}_{32} \mathrm{H}_{38} \mathrm{~N}_{10} \mathrm{CoO}_{8} \mathrm{~S}(\%)$ : C, 49.17; H, 4.90; N, 17.92; S, 4.10. Found: C, 49.20; H, 4.46; N, 17.85; S, 4.86. IR $\left(\mathrm{cm}^{-1}\right): 3242 v(\mathrm{~N}-\mathrm{H}), 1545$ $v(\mathrm{C}=\mathrm{N}), 1037 v_{3}\left(\mathrm{SO}_{4}\right), 226 v(\mathrm{M}-\mathrm{N})$. Conductivity $\left(10^{-3}\right.$ $\left.\mathrm{M}, \mathrm{ohm}^{-1} \cdot \mathrm{cm}^{2} \cdot \mathrm{mole}^{-1}\right): 66$.

$\left[\mathrm{Ni}(\mathrm{NNN})_{2}\right] \mathrm{SO}_{4} \cdot 3 \mathrm{H}_{2} \mathrm{O}$ : Color: purple. Yield $=57 \%$, m.p., $253^{\circ} \mathrm{C}-255^{\circ} \mathrm{C}$. Anal. Calcd. for $\mathrm{C}_{32} \mathrm{H}_{36} \mathrm{~N}_{10} \mathrm{NiO}_{7} \mathrm{~S}$ (\%): C, 50.34; H, 4.75; N, 18.35; S, 4.20. Found: C, 50.64; H, 4.74; N, 18.28; S, 4.10. IR $\left(\mathrm{cm}^{-1}\right): 3234 v(\mathrm{~N}-\mathrm{H})$, $1538 v(\mathrm{C}=\mathrm{N}), 1037 v_{3}\left(\mathrm{SO}_{4}\right), 230 v(\mathrm{M}-\mathrm{N})$. Conductivity $\left(10^{-3} \mathrm{M}, \mathrm{ohm}^{-1} \cdot \mathrm{cm}^{2} \cdot \mathrm{mole}^{-1}\right): 69$.

$\left[\mathrm{Cu}(\mathrm{NNN})_{2}\right] \mathrm{SO}_{4} \cdot 7 \mathrm{H}_{2} \mathrm{O}$ : Color: green. Yield $=65 \%$, m.p., $228^{\circ} \mathrm{C}-229^{\circ} \mathrm{C}$. Anal. Calcd. for $\mathrm{C}_{32} \mathrm{H}_{44} \mathrm{~N}_{10} \mathrm{CuO}_{11} \mathrm{~S}$ (\%): C, 45.74; H, 5.28; N, 16.67; S, 3.82. Found: C, 45.81; H, 5.11; N, 16.41; S, 3.44. IR $\left(\mathrm{cm}^{-1}\right): 3233 v(\mathrm{~N}-\mathrm{H})$, $1565 v(\mathrm{C}=\mathrm{N}), 1060-1088 v_{3}\left(\mathrm{SO}_{4}\right), 224 v(\mathrm{M}-\mathrm{N})$. Conductivity $\left(10^{-3} \mathrm{M}, \mathrm{ohm}^{-1} \cdot \mathrm{cm}^{2} \cdot \mathrm{mole}^{-1}\right): 71$.

$\left[\mathrm{Zn}(\mathrm{NNN})_{2}\right] \mathrm{SO}_{4} \cdot 11 \mathrm{H}_{2} \mathrm{O}$ : Color: white. Yield $=64 \%$, m.p., $221^{\circ} \mathrm{C}-222^{\circ} \mathrm{C}$. Anal.Calcd. for $\mathrm{C}_{32} \mathrm{H}_{52} \mathrm{~N}_{10} \mathrm{ZnO}_{15} \mathrm{~S}$ (\%): C, 42.04; H, 5.73; N, 15.31; S, 3.51. Found: C, 41.96; H, 5.71; N, 15.00; S, 3.59. IR $\left(\mathrm{cm}^{-1}\right): 3227 \mathrm{v}(\mathrm{N}-\mathrm{H})$, $1548 v(\mathrm{C}=\mathrm{N}), 1037 v_{3}\left(\mathrm{SO}_{4}\right), 222 v(\mathrm{M}-\mathrm{N})$. Conductivity $\left(10^{-3} \mathrm{M}, \mathrm{ohm}^{-1} \cdot \mathrm{cm}^{2} \cdot \mathrm{mole}^{-1}\right): 82$.

\subsubsection{Sulfonate Complexes}

$\left[\mathrm{Co}(\mathrm{NNN})_{2}\right]\left(\mathrm{RSO}_{3}\right)_{2} \cdot 4 \mathrm{H}_{2} \mathrm{O} \cdot 2 \mathrm{EtOH}$ : Color: red. Yield $=$ $71 \%$, m.p., $225^{\circ} \mathrm{C}-226^{\circ} \mathrm{C}$. Anal. Calcd. for $\mathrm{C}_{50} \mathrm{H}_{64} \mathrm{~N}_{10^{-}}$ $\mathrm{CoO}_{12} \mathrm{~S}_{2}$ (\%): C, 53.66; H, 5.67; N, 12.52; S, 5.73. Found: C, 53.60; H, 5.34; N, 12.67; S, 5.14. IR $\left(\mathrm{cm}^{-1}\right): 3311$ $v(\mathrm{~N}-\mathrm{H}), 1551 \quad v(\mathrm{C}=\mathrm{N}), \quad 1150-1161 \quad v_{3}\left(\mathrm{RSO}_{3}\right), 279$ $\mathrm{v}(\mathrm{M}-\mathrm{N})$. Conductivity $\left(10^{-3} \mathrm{M}, \mathrm{ohm}^{-1} \cdot \mathrm{cm}^{2} \cdot \mathrm{mole}^{-1}\right): 136$.

$\left[\mathrm{Ni}(\mathrm{NNN})_{2}\right]\left(\mathrm{RSO}_{3}\right)_{2} \cdot 3 \mathrm{H}_{2} \mathrm{O} \cdot 2 \mathrm{EtOH}$ : Color: purple. Yield $=58 \%$, m.p., $246^{\circ} \mathrm{C}-248^{\circ} \mathrm{C}$. Anal. Calcd. for $\mathrm{C}_{50} \mathrm{H}_{62-}$ $\mathrm{N}_{10} \mathrm{NiO}_{11} \mathrm{~S}_{2}(\%)$ : C, 54.50; H, 5.67; N, 12.71; S, 5.82. Found: C, 54.43; H, 5.58; N, 12.47; S, 5.70. IR $\left(\mathrm{cm}^{-1}\right)$ : $3313 v(\mathrm{~N}-\mathrm{H}), 1550 v(\mathrm{C}=\mathrm{N}), 1151-1164 v_{3}\left(\mathrm{RSO}_{3}\right), 246$ $v(\mathrm{M}-\mathrm{N})$. Conductivity $\left(10^{-3} \mathrm{M}\right.$, ohm $\left.{ }^{-1} \cdot \mathrm{cm}^{2} \cdot \mathrm{mole}^{-1}\right): 139$.

$\left[\mathrm{Cu}(\mathrm{NNN})_{2}\right]\left(\mathrm{RSO}_{3}\right)_{2} \cdot 12 \mathrm{H}_{2} \mathrm{O}$ : Color: blue. Yield $=68 \%$, m.p., $201^{\circ} \mathrm{C}-202^{\circ} \mathrm{C}$. Anal. Calc. for $\mathrm{C}_{46} \mathrm{H}_{68} \mathrm{~N}_{10} \mathrm{CuO}_{18} \mathrm{~S}_{2}$ (\%): C, 46.95; H, 5.82 N, 11.90; S, 5.45. Found: C, 46.48; $\mathrm{H}, 5.47 ; \mathrm{N}, 11.76 ; \mathrm{S}, 5.85$. IR $\left(\mathrm{cm}^{-1}\right): 3213 v(\mathrm{~N}-\mathrm{H}), 1550$ $v(\mathrm{C}=\mathrm{N}), 1147-1172 v_{3}\left(\mathrm{RSO}_{3}\right), 262 v(\mathrm{M}-\mathrm{N})$. Conductivity $\left(10^{-3} \mathrm{M}, \mathrm{ohm}^{-1} \cdot \mathrm{cm}^{2} \cdot \mathrm{mole}^{-1}\right): 141$. 
$\left[\mathrm{Zn}(\mathrm{NNN})_{2}\right]\left(\mathrm{RSO}_{3}\right)_{2} \cdot 3 \mathrm{H}_{2} \mathrm{O} \cdot 2 \mathrm{EtOH}$ : Color: white. Yield $=62 \%$, m.p., $201^{\circ} \mathrm{C}-202^{\circ} \mathrm{C}$. Anal. Calc. for $\mathrm{C}_{50} \mathrm{H}_{62} \mathrm{~N}_{10^{-}}$ $\mathrm{ZnO}_{11} \mathrm{~S}_{2}(\%): \mathrm{C}, 54.17 ; \mathrm{H}, 5.64 ; \mathrm{N}, 12.63 ; \mathrm{S}, 5.78$. Found: C, 54.50; H, 5.64; N, 12.30; S, 5.53. IR $\left(\mathrm{cm}^{-1}\right): 3304$ $v(\mathrm{~N}-\mathrm{H}), \quad 1549 v(\mathrm{C}=\mathrm{N}), 1172-1187 \quad v_{3}\left(\mathrm{RSO}_{3}\right), 258$ $v(\mathrm{M}-\mathrm{N})$. Conductivity $\left(10^{-3} \mathrm{M}, \mathrm{ohm}^{-1} \cdot \mathrm{cm}^{2} \cdot \mathrm{mole}^{-1}\right): 147$.

\subsection{Solvent Extraction Procedure}

All the extractions were carried out at $25^{\circ} \mathrm{C}\left( \pm 1^{\circ} \mathrm{C}\right)$ in a temperature controlled laboratory. Equal volumes (10 $\mathrm{mL}$ ) of $0.001 \mathrm{M}$ metal ion solution (aqueous layer) and $80 \%$ 2-octanol/shellsol solution (organic layer containing the extractant BDNNN and the counterion DNNSA) were pipetted into $50 \mathrm{~mL}$ conical separating funnels. The contents in the funnel were shaken using an automated orbital platform shaker for 30 minutes at an optimised speed of $200 \mathrm{rpm}$. A minimum period of 60 minutes was observed before harvesting the raffinates. The raffinates were filtered through a $33 \mathrm{~mm}$ millex-HV Millipore filter $(0.45 \mu \mathrm{m})$ and diluted appropriately for analysis by ICP. The percentage extractions $(\% \mathrm{E})$ of the metal ions were calculated from the concentrations of the metal ions in the aqueous phase using equation 1 below:

$$
\% \mathrm{E}=\left(\frac{C_{i}-C_{s}}{C_{i}}\right) \times 100
$$

where $C_{i}$ is the initial solution concentration $(\mathrm{mg} / \mathrm{L})$ and $C_{s}$ is the solution concentration after extraction.

The extraction efficiencies were investigated as a function of $\mathrm{pH}$, and all the extraction curves were plotted with Sigma Plot 11.0.

\subsection{X-Ray Structure Determination and Refinement}

Single crystals of $\left[\mathrm{Cu}(\mathrm{NNN})_{2}\right]\left(\mathrm{RSO}_{3}\right)_{2} \cdot 12 \mathrm{H}_{2} \mathrm{O}$, suitable for X-ray diffraction, were obtained by slow evaporation of the ethanolic mother liquor of this complex at room temperature. X-ray diffraction studies were performed at $200 \mathrm{~K}$ using a Bruker Kappa Apex II diffractometer with graphite monochromated Mo $\mathrm{K} \alpha$ radiation $(\lambda=0.71073$ $\AA)$. The crystal structures were solved by direct methods using SHELXTL [16]. All non-hydrogen atoms were refined anisotropically. C-bound $\mathrm{H}$ atoms were placed in calculated positions and refined as riding atoms, with bond lengths 0.95 (aromatic $\mathrm{CH}), 0.99\left(\mathrm{CH}_{2}\right), 0.98\left(\mathrm{CH}_{3}\right)$ $\AA$ and with $U_{\text {iso }}(\mathrm{H})=1.2$ (1.5 for methyl) $U_{\text {eq }}(\mathrm{C})$. Hydrogens bonded to nitrogen were located on a Fourier map and allowed to refine freely. Hydrogens on water molecules were restrained to an $\mathrm{O}-\mathrm{H}$ bond length of 0.84 $\AA$ and $\mathrm{H}-\mathrm{O}-\mathrm{H}$ angle of $110^{\circ}$. Diagrams and publication material were generated using SHELXTL, PLATON [17] and ORTEP-3 [18].

\section{Results and Discussion}

\subsection{Solvent Extraction Studies}

These studies were carried out in dilute synthetic sulfate solutions. The extractant (BDNNN) was used for the extraction studies while the ligand (NNN) was used to study the coordination chemistry involved. The complexes of the extractant were oily and not easily isolated hence we used the NNN ligand for the coordination chemistry studies. The decyl groups of the extractant (BDNNN) would be positioned away from the coordination sphere and therefore the use of the ligand (NNN) would not change the coordination chemistry of the extractant from a steric hindrance point of view.

The use of low $\mathrm{p} K_{\mathrm{a}}$ groups (benzimidazoles) on the ligand was expected to result in metal extractions from highly acidic solutions in comparison with tridentate aliphatic amine extractants based on diethylenetriamine [9]. This was well exploited but also resulted in lack of room for back-extraction of some metals (like $\mathrm{Cu}$ (II), $\mathrm{Co}$ (II) and possibly $\mathrm{Ni}(\mathrm{II})$ ) at the "left legs" of their extraction curves. The lack of $\mathrm{pH}$-metric separation of the base metal ions, however, was evident from the small $\Delta \mathrm{pH}_{0.5}$ values (Figure 2). Interestingly, the order of the extraction of the metal ions somewhat followed the IrvingWilliams stability order [19] in the shifting of the curves towards the acidic region with the exception of $\mathrm{Co}$ (II) and Ni(II) extractions, which could be influenced by kinetic effects [20]. It is also noteworthy to report on the hard ions $\left(\mathrm{Mn}^{2+}\right.$ and $\left.\mathrm{Mg}^{2+}\right)$ extracting ability of this tridentate ligand but with rejection of $\mathrm{Fe}(\mathrm{III})$ in the $\mathrm{pH}$ range $0-2.6$, which is attractive for the latter but not the former.

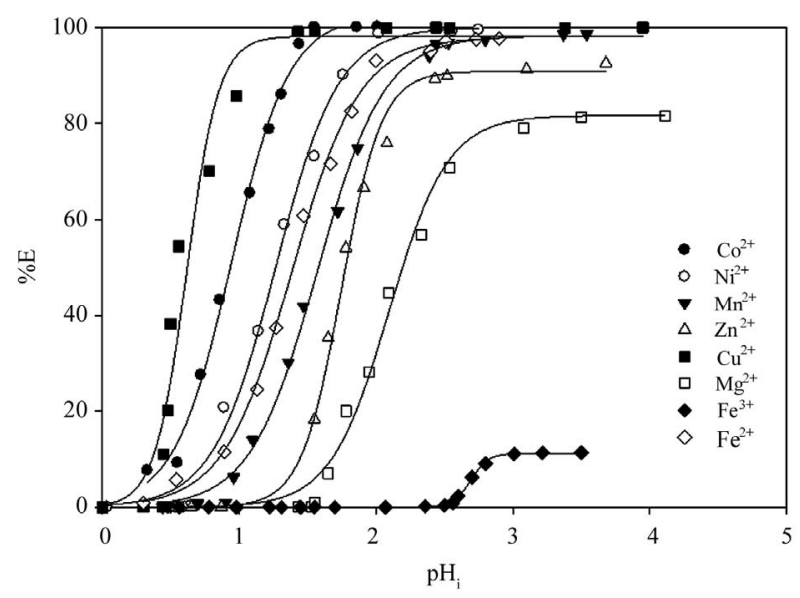

Figure 2. A plot of $\% \mathrm{E}$ vs initial $\mathrm{pH}$ of equimolar concentrations (0.001 M) of $\mathrm{Mg}^{2+}, \mathrm{Mn}^{2+}, \mathrm{Fe}^{3+}, \mathrm{Fe}^{2+}, \mathrm{Co}^{2+}, \mathrm{Ni}^{2+}$, $\mathrm{Cu}^{2+}$ and $\mathrm{Zn}^{2+}$, extracted with BDNNN (at M:L ratio 1:40) and $0.02 \mathrm{M}$ DNNSA in 2-octanol/Shellsol 2325 (8:2) from a dilute sulfate medium. 
It is clear, therefore, that the move towards tridentate ligands, even with low $\mathrm{p} K_{\mathrm{a}}$ aromatic nitrogen groups and a strong aliphatic amine group, is not sufficient to successfully exploit the low $\mathrm{pH}$ range interactions with $\mathrm{m}$ etal ions since extraction isotherms are pushed further into the low $\mathrm{pH}$ range thereby compromising back-extraction. These ligands also lack selectivity for the important borderline metal ions which can possibly be tuned through bonding preferences. The coordination chemistry studies (Section 3.2) were, therefore, conducted to try and elucidate the underlying aspects of bonding that influenced the extraction isotherms observed.

In a quantitative treatment for this solvent extraction system, similar to that applied for a chelating system (HL) [6], the protonation, complexation and phase distribution equilibria can be used to describe the system mathematically with respect to the distribution ratio of a metal ion $\left(\mathrm{M}^{\mathrm{n}+}\right)$, and also give insight into the coordination numbers involved in the extraction reaction. The protonation equilibria which were studied using potentiometry in the $\mathrm{pH}$ range of 2 - 10 by Hay et al. [7] showed two constants for bis((1H-benzimidazol-2-yl)methyl)amine (NN$\mathrm{N}, \mathrm{L}$ ), and they were 5.64 and 10.12 respectively for the cumulative protonation steps $\left(\mathrm{LH}^{+}\right.$and $\left.\mathrm{LH}_{2}^{2+}\right)$. The species distribution plot, constructed from the above constants using the computer program HYSS [21], is given in Figure 3 for the $\mathrm{pH}$-metric speciation involved for $\mathrm{L}$ in the aqueous phase.

The chelating agent (L) must distribute between the organic and aqueous phases to effect coordination in the aqueous phase, and that distribution coefficient is represented by $K_{\mathrm{D}}(\mathrm{L})$ :

$$
(\mathrm{L})_{\mathrm{a}} \square(\mathrm{L})_{\mathrm{o}} \text { and } K_{\mathrm{D}}(\mathrm{L})=\frac{[\mathrm{L}]_{\mathrm{o}}}{[\mathrm{L}]_{\mathrm{a}}}
$$

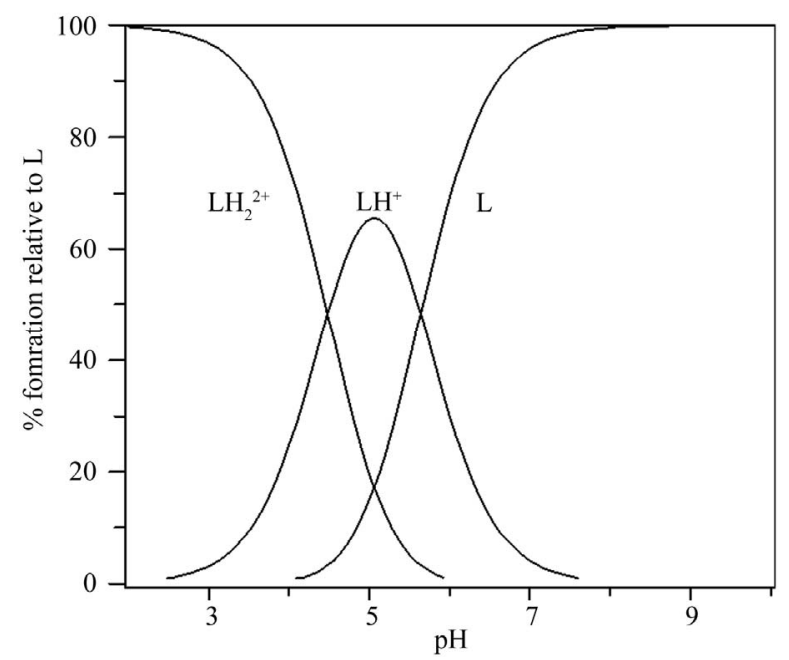

Figure 3. Protonation species distribution diagram for bis((1H- benzimidazol-2-yl)methyl)amine (NNN, L).
However, in the aqueous phase the following two protonation equilibria may exist depending on $\mathrm{pH}$ :

$$
\begin{aligned}
& \mathrm{LH}_{2}^{2+} \square \mathrm{H}^{+}+\mathrm{LH}^{+}, K_{\mathrm{a} 1}=\frac{\left[\mathrm{H}^{+}\right]_{\mathrm{a}}\left[\mathrm{LH}^{+}\right]_{\mathrm{a}}}{\left[\mathrm{LH}_{2}^{2+}\right]_{\mathrm{a}}} \\
& \mathrm{LH}^{+} \square \mathrm{H}^{+}+\mathrm{L} \text { and } K_{\mathrm{a} 2}=\frac{\left[\mathrm{H}^{+}\right]_{\mathrm{a}}\left[\mathrm{LH}^{+}\right]_{\mathrm{a}}}{\left[\mathrm{LH}^{+}\right]_{\mathrm{a}}}
\end{aligned}
$$

Then, the metal ion chelates with the neutral ligand to form a cationic complex:

$$
\mathrm{M}^{\mathrm{n}+}+\mathrm{mL} \square \mathrm{ML}_{\mathrm{m}}^{\mathrm{n}+} \text { and } K_{\mathrm{f}}=\frac{\left[\mathrm{ML}_{\mathrm{m}}^{\mathrm{n}+}\right]_{\mathrm{a}}}{\left[\mathrm{M}^{\mathrm{n}+}\right][\mathrm{L}]_{\mathrm{a}}^{\mathrm{m}}}
$$

It must be borne in mind, however, that the metal ion will replace proton(s) in the $\mathrm{pH}$ ranges under investigation but the protonation equilibria will accommodate this in the mathematical treatment. Finally, the chelate which is ion-paired by an anion (in our case two sulfonate anions represented by $\mathrm{X}^{\mathrm{n}-}$ ) to form an extractible species, $\left[\mathrm{ML}_{\mathrm{m}}\right] \mathrm{X}$, distributes itself between the organic and aqueous phases:

$$
\begin{gathered}
\left(\mathrm{ML}_{\mathrm{m}}^{\mathrm{n}+}\right)_{a}+\left(\mathrm{X}^{\mathrm{n}-}\right)_{\mathrm{o} / \mathrm{a}} \square\left(\mathrm{ML}_{\mathrm{m}} \mathrm{X}\right)_{\mathrm{o}} \text { and } \\
K_{\mathrm{D}}\left(\mathrm{ML}_{\mathrm{m}}^{\mathrm{n}+}\right)=\frac{\left[\mathrm{ML}_{\mathrm{m}} \mathrm{X}\right]_{\mathrm{o}}}{\left[\mathrm{ML}_{\mathrm{m}}^{\mathrm{n}}\right]_{\mathrm{a}}}
\end{gathered}
$$

The distribution ratio (D), defined as the ratio of the concentration of the total metal species in the organic phase to that in the aqueous (regardless of its mode), is given by expression 7 , on the assumption that the metal chelate distributes largely in the organic phase and that the metal ion does not hydrolyse in the aqueous phase.

$$
\mathrm{D} \approx \frac{\left[\mathrm{ML}_{\mathrm{m}} \mathrm{X}\right]_{\mathrm{o}}}{\left(\mathrm{M}^{\mathrm{n}+}\right)_{\mathrm{a}}}
$$

Substituting Equations (6) and (5) respectively into Equation (7) yields Equation (8), depicting the formation constant and the concentration of the ligand in the aqueous phase as important parameters as well as the distribution coefficient of the chelate:

$$
\mathrm{D}=K_{\mathrm{D}}\left(\mathrm{ML}_{\mathrm{m}}^{\mathrm{n}+}\right) K_{\mathrm{f}}[\mathrm{L}]_{\mathrm{a}}^{\mathrm{m}}
$$

which can be transformed to Equation (9) if Equation (2) is substituted into Equation (8), indicating that the concentration of $\mathrm{L}$ in the aqueous phase is dependent on its concentration in the organic phase and that its distribution between the two phases affects the distribution ratio of the complex formed: 


$$
\mathrm{D}=\frac{K_{\mathrm{D}}\left(\mathrm{ML}_{\mathrm{m}}^{\mathrm{n}+}\right) K_{\mathrm{f}}}{K_{\mathrm{D}}(\mathrm{L})^{\mathrm{m}}}[\mathrm{L}]_{\mathrm{o}}^{\mathrm{m}}
$$

However, since the extractions are carried out at low $\mathrm{pH}$, it is necessary to consider the two protonation equilibria respectively because these species occur over wide $\mathrm{pH}$ ranges (Figure 3), and competition of metal ions with protons for the ligand occurs early with $\mathrm{pH}$ due to the higher formation constants [7] compared with protonation constants thereby resulting in release of the protons from the ligand. Now, substituting Equation (4), and Equations (3) and (4), respectively, into Equation (8) yields the following respective Equations (10) and (11):

$$
\begin{gathered}
\mathrm{D}=K_{\mathrm{D}}\left(\mathrm{ML}_{\mathrm{m}}^{\mathrm{n}+}\right) K_{\mathrm{f}} K_{\mathrm{a} 2}^{\mathrm{m} 2} \frac{\left[\mathrm{LH}^{+}\right]^{\mathrm{m}}}{\left[\mathrm{H}^{+}\right]_{\mathrm{a}}^{\mathrm{m}}} \\
\text { And } \mathrm{D}=K_{\mathrm{D}}\left(\mathrm{ML}_{\mathrm{m}}^{\mathrm{n}+}\right) K_{\mathrm{f}} K_{\mathrm{a} 2}^{\mathrm{m}} K_{\mathrm{a} 1}^{\mathrm{m} 1} \frac{\left[\mathrm{LH}_{2}^{2+}\right]_{\mathrm{a}}^{\mathrm{m}}}{\left[\mathrm{H}^{+}\right]_{\mathrm{a}}^{2 \mathrm{~m}}}
\end{gathered}
$$

Therefore, in the $\mathrm{pH}$ range where only one protonation equilibrium (Equation (4)) is involved then a plot of $\log$ $\mathrm{D} \mathrm{vs} \mathrm{pH}$ (from taking the logarithms of both sides in equation 10) should yield a straight line with slope $m$ (number of ligands bonded to the metal ion $\mathrm{M}^{\mathrm{n}+}$ ). But in the highly acidic region where the second proton equilibrium (Equation (3)) is also active, then a plot of $\log \mathrm{D}$ vs $\mathrm{pH}$ should yield a straight line with slope $(2 \mathrm{~m})$.

A plot of $\log \mathrm{D}$ vs $\mathrm{pHe}$ (since the extraction isotherms relate to the equilibrium condition) for this extraction system is presented in Figure 4. There is a clear change in the slope of each curve and respectively become steeper with an increase in the order of stabilization of metal ions [19]. The higher $\mathrm{pH}$ range for $\mathrm{Mg}^{2+}, \mathrm{Zn}^{2+}$, $\mathrm{Mn}^{2+}, \mathrm{Fe}^{2+}$ and $\mathrm{Ni}^{2+}$ is represented by a slope in the range 1 - 2 with nickel at $\mathrm{m}=1.97$ while it peaks close to $3-4$ $(\approx 2 \mathrm{~m})$ respectively at the lower $\mathrm{pH}$ range with the exception of nickel (slope $=15$ ) which gets seriously affected by the extremely acidic medium. This observation is somewhat in agreement with the mathematical model described here for this complex equilibria system suggesting two ligands per metal ion are involved in the coordination. These observations (as well as those discussed below) are also in line with the protonated ligand species observed in Figure 3 (for the protonation equilibria). The extremely acidic region (affecting the copper and cobalt curves, and to a minor extent the nickel curve in the acidic end) is only characterised by a slope of ca. ( $3 \mathrm{~m}-2 \mathrm{~m}$ ) for copper and cobalt at the higher $\mathrm{pH}$ end (around the $\mathrm{pH}$ where other metal ions also have a slope close to 4). This occurred mainly because our mathematical modelling does not take into account the third protonation equilibrium which is possible under those

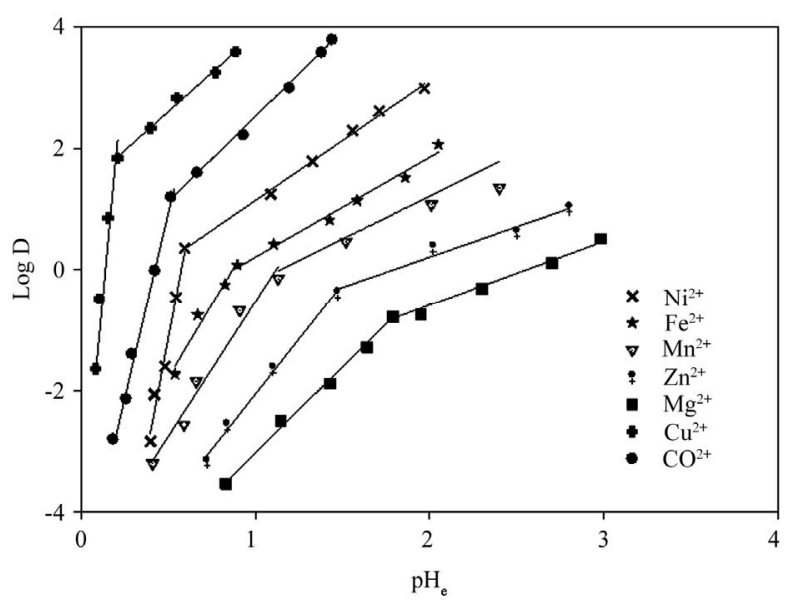

Figure 4. A plot of $\log \mathrm{D}$ vs equilibrium $\mathrm{pH}\left(\mathrm{pH}_{\mathrm{e}}\right)$ for the extraction of $0.001 \mathrm{M} \mathrm{M}^{2+}\left(\mathrm{M}=\mathrm{Mg}^{2+}, \mathrm{Zn}^{2+}, \mathrm{Mn}^{2+}, \mathrm{Fe}^{2+}, \mathrm{Ni}^{2+}\right.$, $\mathrm{Co}^{2+}$ and $\mathrm{Cu}^{2+}$ ) with $0.002 \mathrm{M}$ BDNNN and 0.02 M DNNSA from sulfate medium.

highly acidic conditions where cobalt and copper are extracted. This third protonation constant was also not determined by potentiometry by Hay et al. [7] due to the inaccessibility of the measurement in that $\mathrm{pH}$ range by potentiometry. According to our mathematical treatment, involving the third equilibrium should result in a slope 3 $\mathrm{m}=6$ at the lower $\mathrm{pH}$ end for cobalt and copper (and to some extent nickel), however, it is much steeper with slopes of 12,15 and 26 for cobalt, nickel and copper respectively.

It is possible, however, that not only the double (slope $=2 \mathrm{~m}$ ) and the triple (slope $=3 \mathrm{~m}$ ) protonation equilibria dominate in the $\mathrm{pH}$ range where extractions of copper and cobalt ions occur but complex multiple protonations ( $i \mathrm{~m}, i=1,2,3, \cdots)$ with $i$ exceeding 3 from the hydrogen bonding with the rings' $\pi$ electrons [22], hence the coordination number $(\mathrm{m})$ cannot be calculated accurately from data in that $\mathrm{pH}$ range. It seems though that a linear plot of the points (calculated at the intersections of the two lines from each metal ion extraction data) at the vertices of the two linear plots, respectively for each metal ion, gives a negative slope $\approx 1.6$ which is in agreement with the coordination numbers of 2 involved for all the metals (discussed in Section 3.2), but a mathematical treatment has not been provided herein. This observation may be coincidental, and therefore one cannot conclude on an isolated study. Once it is verified for other extraction studies with extractants similar to the one studied here, a mathematical function may be derived.

\subsection{Coordination Chemistry Studies}

The elemental analyses data suggested the following empirical formulae; $\left[\mathrm{M}(\mathrm{NNN})_{2}\right] \mathrm{X} \cdot x \mathrm{H}_{2} \mathrm{O} \cdot y$ EtOH $(\mathrm{M}=\mathrm{Co}$, $\mathrm{Ni}, \mathrm{Cu}$ and $\mathrm{Zn} ; \mathrm{X}=\mathrm{SO}_{4}^{2-}$ or $\left(\mathrm{RSO}_{3}^{-}\right)_{2}, x=3-12$ and $y$ $=0$ - 2). The involvement of two ligands per metal ion is 
in agreement with what was observed in the extraction studies. Complexes of Fe(II), Fe(III) and other hard ions could not be isolated with a good level of purity but bis-coordination is implied by the slopes of the extraction data. The molar conductivity data in DMF showed that the sulfate and sulfonate complexes have molar conductance values of $66-82$ and $136-147 \Omega^{-1} \cdot \mathrm{cm}^{2} \cdot \mathrm{mol}^{-1}$, respectively. This indicated that all the sulfate complexes behaved as 1:1 electrolytes while the sulfonate complexes were 1:2 electrolytes [23]. This behavior in solution suggested the non-coordinated nature of the counteranions. Both the sulfate and sulfonate complexes were prepared in order to elucidate the nature of these anions respectively with respect to their innocence to coordination, and the full structural analyses are discussed in Sections 3.2.1 and 3.2.2 below. Both the sulfate and sulfonate complexes were prepared since the extraction studies were carried out in a sulfate medium and a bulky sulfonate anion was also used to replace the sulfate ion.

\subsubsection{Spectral Analysis}

The $\mathrm{C}=\mathrm{N}$ stretching vibration of the benzimidazole rings of the free ligand $(\mathrm{NNN})$ appeared at $1592 \mathrm{~cm}^{-1}[24,25]$, and coordination-induced frequencies were observed in the range $1548-1565 \mathrm{~cm}^{-1}$ upon complex formation. The lowering in the double bond character of $\mathrm{C}=\mathrm{N}$ is perhaps due to the influence of the benzimidazole groups being trans to each other. The far infrared spectra of the sulfate and sulfonate complexes displayed bands in the range $222-279 \mathrm{~cm}^{-1}$ which were assigned to the $v(\mathrm{M}-\mathrm{N})$ [26]. A strong and broad peak in the range $1137-1188$ $\mathrm{cm}^{-1}$ and $1050-1090 \mathrm{~cm}^{-1}$ was present in the spectra of sulfate and sulfonate complexes respectively, and this is typical of the uncoordinated sulfate and sulfonate ions [27]. The infrared spectra of these complexes suggested that all the three donor atoms of the ligand are involved in the coordination sphere and that both the sulfate and sulfonate anions are non-coordinating. The geometry of the complexes was confirmed by UV-Vis solid reflectance electronic studies as well as by single crystal X-ray crystallography (Section 3.2.2).

Three d-d transitions that are expected in the visible region of the spectrum for an octahedral $\mathrm{Co}(\mathrm{II})$ complex are; ${ }^{4} \mathrm{~T}_{1 \mathrm{~g}}(\mathrm{~F}) \rightarrow{ }^{4} \mathrm{~T}_{2 \mathrm{~g}}(\mathrm{~F})\left(\mathrm{v}_{1}\right),{ }^{4} \mathrm{~T}_{1 \mathrm{~g}}(\mathrm{~F}) \rightarrow{ }^{4} \mathrm{~A}_{2 \mathrm{~g}}(\mathrm{~F})\left(v_{2}\right)$ and ${ }^{4} \mathrm{~T}_{1 \mathrm{~g}}(\mathrm{~F}) \rightarrow{ }^{4} \mathrm{~T}_{1 \mathrm{~g}}(\mathrm{P})\left(\mathrm{v}_{3}\right)$ [28]. These absorption bands were observed at 1095, 544 and $482 \mathrm{~nm}$ respectively (Figure 5). For the nickel complexes the bands were observed at 919,585 and $555 \mathrm{~nm}$ which may be assigned to ${ }^{3} \mathrm{~A}_{2 \mathrm{~g}}(\mathrm{~F})$ $\rightarrow{ }^{3} \mathrm{~T}_{2 \mathrm{~g}}(\mathrm{~F})\left(\mathrm{v}_{1}\right),{ }^{3} \mathrm{~A}_{1 \mathrm{~g}}(\mathrm{~F}) \rightarrow{ }^{3} \mathrm{~T}_{2 \mathrm{~g}}(\mathrm{~F})\left(\mathrm{v}_{2}\right)$ and $\left({ }^{3} \mathrm{~A}_{2 \mathrm{~g}}(\mathrm{~F}) \rightarrow\right.$ ${ }^{3} \mathrm{~T}_{1 \mathrm{~g}}(\mathrm{P})\left(v_{3}\right)$ transitions respectively for an octahedral symmetry [28]. The electronic spectrum of the $\mathrm{Cu}(\mathrm{II})$ complex showed one broad band at $619 \mathrm{~nm}$ which was ascribed to the ${ }^{2} \mathrm{~B}_{1 \mathrm{~g}} \rightarrow{ }^{2} \mathrm{~B}_{2 \mathrm{~g}}$ and, assuming that the second transition $\left({ }^{2} \mathrm{~B}_{1 \mathrm{~g}} \rightarrow{ }^{2} \mathrm{~A}_{1 \mathrm{~g}}\right)$ is masked by the intraligand transition, this is consistent with a distorted octahedral geometry [28].

\subsubsection{X-Ray Structural Analysis}

An ORTEP diagram of the crystal structure of

$\left[\mathrm{Cu}(\mathrm{NNN})_{2}\right]\left(\mathrm{RSO}_{3}\right)_{2} \cdot \mathbf{1 2 H}_{\mathbf{2}} \mathrm{O}$ is presented in Figure 6. The selected crystallographic data is presented in Table $\mathbf{1}$, and selected bond lengths and angles in Table 2.

The crystal structure of $\left[\mathrm{Cu}(\mathrm{NNN})_{2}\right]\left(\mathrm{RSO}_{3}\right)_{2} \cdot \mathbf{1 2 H}_{2} \mathrm{O}$ conclusively depicted that the complex is cationic with relatively isolated sulfonate anions (Figure 6). The closest contact that the sulfonate ion has with the cationic molecule is $\mathrm{H}(23)-\mathrm{O}(31)=2.560(1)$. The two ligands are

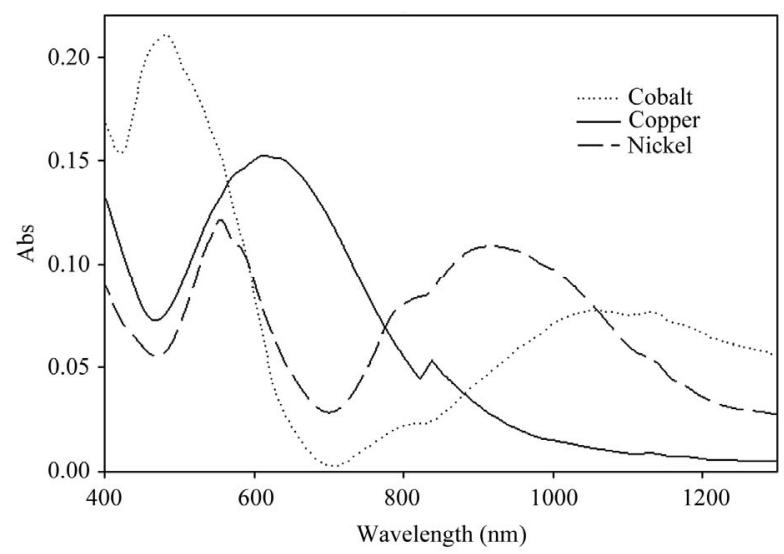

Figure 5. The UV-Vis solid reflectance spectra of $\left[\mathrm{M}(\mathrm{NNN})_{2}\right] \mathrm{SO}_{4} \cdot x \mathrm{H}_{2} \mathrm{O}(\mathrm{M}=\mathrm{Co}, \mathrm{Ni}$ and $\mathrm{Cu} ; x=3-12)$.

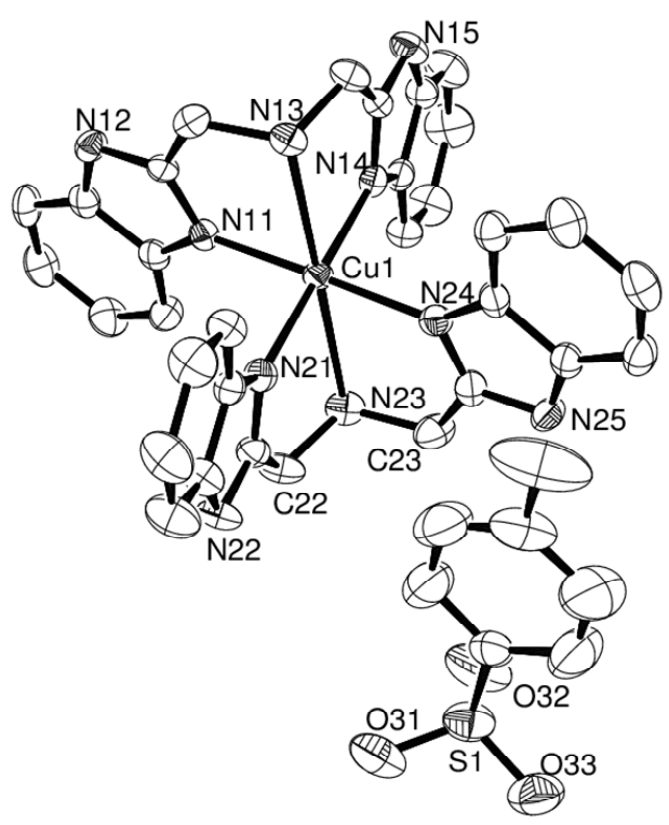

Figure 6. ORTEP diagram of $\left[\mathrm{Cu}(\mathrm{NNN})_{2}\right]\left(\mathrm{RSO}_{3}\right)_{2} \cdot 12 \mathrm{H}_{2} \mathrm{O}$ showing the atom labeling scheme and ellipsoids drawn at $50 \%$ probability level. One toluene-4-sulfonate anion and twelve water molecules have been omitted for clarity. 
Table 1. Selected crystallographic data for $\left[\mathrm{Cu}(\mathrm{NNN})_{2}\right]\left(\mathrm{RSO}_{3}\right)_{2} \cdot \mathbf{1 2} \mathrm{H}_{2} \mathrm{O}$.

\begin{tabular}{|c|c|}
\hline Compound & {$\left[\mathrm{Cu}(\mathrm{NNN})_{2}\right]\left(\mathrm{RSO}_{3}\right)_{2} \cdot 12 \mathrm{H}_{2} \mathrm{O}$} \\
\hline Chemical formula & $\mathrm{C}_{54} \mathrm{H}_{86} \mathrm{CuN}_{10} \mathrm{O}_{18} \mathrm{~S}_{2}$ \\
\hline Formulae weight & 4514.66 \\
\hline Crystal color & Blue \\
\hline Crystal system & Tetragonal \\
\hline Space group & 14 \\
\hline Temperature $(\mathrm{K})$ & 200 \\
\hline Crystal size $\left(\mathrm{mm}^{3}\right)$ & $0.05 \times 0.11 \times 0.50$ \\
\hline $\mathrm{a}(\AA)$ & $34.4165(11)$ \\
\hline $\mathrm{b}(\AA)$ & $34.4165(11)$ \\
\hline $\mathrm{c}(\AA)$ & $9.3238(4)$ \\
\hline$\alpha\left(^{\circ}\right)$ & 90 \\
\hline$\beta\left(^{\circ}\right)$ & 90 \\
\hline$\gamma\left({ }^{\circ}\right)$ & 90 \\
\hline $\mathrm{V}\left(\AA^{3}\right)$ & $11044.0(9)$ \\
\hline Z & 2 \\
\hline$D_{\text {calc }}\left(\mathrm{g} / \mathrm{cm}^{-3}\right)$ & 1.358 \\
\hline$\mu / \mathrm{mm}^{-1}$ & 0.545 \\
\hline $\mathrm{F}(000)$ & 4696 \\
\hline Wavelength $(\AA)$ & 0.71073 \\
\hline Theta Min-Max $\left({ }^{\circ}\right)$ & $1.9,28.3$ \\
\hline S & 0.98 \\
\hline Tot., Uniq. Data, R(int) & $91906,13572,0.095$ \\
\hline Observed data $[\mathrm{I}>2.0 \operatorname{sigma}(\mathrm{I})]$ & 8997 \\
\hline$R$ & 0.0507 \\
\hline$R_{\mathrm{w}}$ & 0.1218 \\
\hline
\end{tabular}

tridentately coordinated to the copper(II) ion in the formation of a tetragonally distorted $\mathrm{O}_{\mathrm{h}}$ geometry with the four benzimidazoles in the square plane while the two aliphatic amines occupy the apical positions. The fivemembered chelate rings have bite angles in the range $74.8^{\circ}-77.0^{\circ}$. The aliphatic amines are bonded trans to each other and the $\mathrm{Cu}-\mathrm{N}$ lengths of 2.509 and $2.547 \AA$ are rather long possibly due to Jahn-Teller distortion. However, the $\mathrm{Cu}-\mathrm{N}$ (benzimidazole) lengths are rather short (average of $2.014 \AA$ ) due to the $\pi$-acidity character of the benzimidazole group.

An X-ray crystal structure of the copper complex similar to $\left[\mathrm{Cu}(\mathrm{NNN})_{2}\right]\left(\mathrm{RSO}_{3}\right)_{2} \cdot 12 \mathrm{H}_{2} \mathrm{O}$ was presented by Berends and Stephan [29] but no crystallographic pa-
Table 2. Selected bond lengths $(\AA)$ and angles $\left(^{\circ}\right)$ for $\left[\mathrm{Cu}(\mathrm{NNN})_{2}\right]\left(\mathrm{RSO}_{3}\right)_{2} \cdot \mathbf{1 2 H}_{2} \mathrm{O}$.

\begin{tabular}{cccc}
\hline \multicolumn{5}{c}{ Bond lengths } \\
\hline Cu1-N11 & $1.998(14)$ & Cu1-N21 & $2.045(14)$ \\
Cu1-N13 & $2.509(14)$ & Cu1-N23 & $2.547(14)$ \\
Cu1-N14 & $2.040(14)$ & Cu1-N24 & $2.012(15)$ \\
\hline \multicolumn{4}{c}{ Bond angles } \\
\hline N11-Cu1-N13 & $77.0(5)$ & N13-Cu1-N24 & $104.0(5)$ \\
N11-Cu1-N14 & $86.5(6)$ & N14-Cu1-N21 & $179.9(8)$ \\
N11-Cu1-N21 & $93.6(6)$ & N14-Cu1-N23 & $105.3(5)$ \\
N11-Cu1-N23 & $103.1(5)$ & N14-Cu1-N24 & $93.9(6)$ \\
N11-Cu1-N24 & $179.0(6)$ & N21-Cu1-N23 & $74.8(5)$ \\
N13-Cu1-N14 & $75.9(5)$ & N21-Cu1-N24 & $86.0(6)$ \\
N13-Cu1-N21 & $104.0(5)$ & N23-Cu1-N24 & $75.9(5)$ \\
N13-Cu1-N23 & $178.9(4)$ & C22-N23-C23 & $114.2(14)$ \\
\hline
\end{tabular}

rameters were reported because the complete refinement of the model was unsuccessful, and the ORTEP diagram presented was based on parameters obtained in "best" model. A similar nickel complex crystal structure has also been reported $[30,31]$ but had a different arrangement of the donor groups, for example the aliphatic amine groups from each ligand were bonded trans to the benzimidazole group of another ligand. The similarity in the geometry of these base metal complexes afforded us to conclude that the lack of $\mathrm{pH}$-metric separation with the use of bis((1-decylbenzimidazol-2-yl)methyl)amine as extractant (Section 3.1) is influenced by the lack of stereochemical "tailor making".

\section{Conclusion}

The combination of two low $\mathrm{p} K_{\mathrm{a}}$ aromatic nitrogenous groups of benzimidazole with a strong aliphatic amine, in the design of a tridentate ligand, resulted in extraction curves that are pushed deep as a function of $\mathrm{pH}$ possibly due to the high complex formation constants of tridentate coordination and the relatively low protonation constants of the benzimidazole groups. This may compromise the stripping of the metal ions from the loaded organic phase through $\mathrm{pH}$ adjustment to lower $\mathrm{pH}$. The Fe(III) rejection ability of this tridentate ligand in the range where the other later $3 \mathrm{~d}$ metal ions extract is remarkable. It can be concluded that the exploitation of the subtle stereochemical aspects of coordination for the extraction of base metals is lacking with tridentate ligands (at least those of the nature presented here). This leads us to propose the evaluation of a bidentate derivative, [2-methylaminomethyl-(1- $R$-benzimidazole), $R=$ octyl or decyl], 
as a potential extractant of base metal ions. We have also demonstrated, for the first time, that the ion-association solvent extraction system studied here can be interpreted quantitatively for the complexation aspect of the formation of the cationic complex species to describe the two linear $\log \mathrm{D} v \mathrm{pH}_{\mathrm{e}}$ plots, and to extract information on coordination numbers from the extraction data using the respective slopes for each extraction curve.

\section{Supporting Information}

CCDC 891865 contains the supplementary crystallographic data for $\left[\mathrm{Cu}(\mathrm{NNN})_{2}\right]\left(\mathrm{RSO}_{3}\right)_{2} \cdot 12 \mathrm{H}_{2} \mathrm{O}$. These data can be obtained free of charge via

www.ccdc.cam.ac.uk/ data request/cif [or from the Cambridge Crystallographic Data Centre (CCDC), 12 Union Road, Cambridge CB2 1EZ, UK; fax: +44(0)1223 - 336033; e-mail: deposit@c-cdc.cam.ac.uk].

\section{Acknowledgements}

The authors thank Mr F. Chindeka (DST/Mintek-NIC, Rhodes University Chemistry Department) for the microanalysis results. We also acknowledge Shell Chemicals (SA) (Pty) Ltd for supplying Shellsol 2325. We would also like to thank Mr A. S. Ogunlaja and Mr P. Kleyi for their assistance. For financial support, we thank the National Research Foundation (NRF-CPRR grant).

\section{REFERENCES}

[1] C. Kumar, S. K. Sahu and B. D. Pandey, "Prospects for Solvent Extraction Process in the Indian Context for Recovery of Base Metals. A Review," Hydrometallurgy, Vol. 103, No. 1-4, 2010, pp. 45-53. doi:10.1016/j.hydromet.2010.02.016

[2] K. C. Sole, A. M. Feather and P. M. Cole, "Solvent Extraction in Southern Africa: An Update of Some Recent Hydrometallurgical Developments," Hydrometallurgy, Vol. 78, No. 1-2, 2005, pp. 52-78. doi:10.1016/j.hydromet.2004.11.012

[3] A. I. Okewole, N. P. Magwa and Z. R. Tshentu, "The Separation of Nickel(II) from Base Metal Ions Using 1-Octyl-2-(2'-pyridyl)imidazole as Extractant in a Highly Acidic Sulfate Medium," Hydrometallurgy, Vol. 121-124, 2012, pp. 81-89. doi:10.1016/j.hydromet.2012.04.002

[4] J. G. H. du Preez, J. Postma, S. Ravindran and B. J. A. M. van Brecht, "Nitrogen Reagents in Metal Ion Separation. Part VI. 2-(1'-Octylthiomethyl)pyridine as Extractant for Later 3d Transition Metal Ions," Solvent Extraction and Ion Exchange, Vol. 15, No. 1, 1997, pp. 79-96. doi:10.1080/07366299708934467

[5] J. G. H. du Preez, "Recent Advances in Amines as Separating Agents for Metal Ions," Solvent Extraction and Ion Exchange, Vol. 18, No. 4, 2000, pp. 679-701. doi:10.1080/07366290008934703

[6] G. D. Christian, "Analytical Chemistry," 6th Edition, John Wiley and Sons Inc, Hoboken, 2003, pp. 444-445.
[7] R. W. Hay, T. C. Clifford and P. Lightfoot, "Copper(II) and Zinc(II) Complexes of N,N-Bis(benzimidazole-2-ylmethyl)-amine. Synthesis, Formation Constants and the Crystal Structure of $\left.[\mathrm{ZnLCl}]_{2}\right] \cdot \mathrm{MeOH}$. Catalytic Activity of the Complexes in the Hydrolysis of the Phosphotriester 2,4-Dinitrophenyl Diethyl Phosphate," Polyhedron, Vol. 17, No. 20, 1998, pp. 3575-3581. doi:10.1016/S0277-5387(98)00152-1

[8] B. Kurzak, D. Kroczewska and J. Jezierska, "Ternary Copper(II) Complexes with Diethylenetriamine and $\alpha$-(or $\beta$-) Alaninehydroxamic Acids in Water Solution," Polyhedron, Vol. 17, No. 11, 1998, pp. 1831-1841. doi:10.1016/S0277-5387(97)00528-7

[9] S. O. Bondareva, Y. I. Murinov and V. V. Lisitskii, "Extraction of Non-Ferrous Metals by Bisacylated Diethylenetriamine," Russian Journal of Inorganic Chemistry, Vol. 52, No. 5, 2007, pp. 796-799. doi:10.1134/S0036023607050257

[10] J. G. H. du Preez, T. I. A. Gerber, W. Edge, V. L. V. Mtotywa and B. J. A. M. van Brecht, "Nitrogen Reagents in Metal Ion Separation. Part XI. The Synthesis and Extraction Behavior of a New Imidazole Derivative," Solvent Extraction and Ion Exchange, Vol. 19, No. 1, 2001, pp. 143-154. doi:10.1081/SEI-100001379

[11] G. Wilkinson, J. A. McCleverty, and R. D. Gillard, Eds., Comprehensive Coordination Chemistry, Late Transition Elements, Vol. 5, Pergamon Press, 1987, pp. 596-681.

[12] K. A. Allen, "Equilibrium between Didecylamine and Sulphuric Acid," Journal of Physical Chemistry, Vol. 60, No. 7, 1956, pp. 943-946. doi:10.1021/j150541a027

[13] B. R. Reddy, S. V. Rao and K. H. Park, "Solvent Extraction Separation and Recovery of Cobalt and Nickel from Sulphate Medium using Mixtures of Tops 99 and TIBPS Extractants," Minerals Engineering, Vol. 22, No. 5, 2009, pp. 500-505. doi:10.1016/j.mineng.2009.01.002

[14] J. V. Dagdigian and C. A. Reed, "A New Series of Imidazole-Thioether Chelating Ligands for Bioinorganic Copper," Inorganic Chemistry, Vol. 18, No. 9, 1979, pp. 2623-2626. doi:10.1021/ic50199a058

[15] M. Haring, "A Novel Route to N-Substituted Heterocycles," Helvetica Chimica Acta, Vol. 42, 1957, pp. 18451850 .

[16] Bruker SHELXTL Version 5.1. (Includes XS, XL, XP, XSHELL), Bruker AXS Inc., Madison, Wisconsin, USA, 1999.

[17] A. L. Spek, "Single-Crystal Structure Validation with the Program PLATON," Journal of Applied Crystallography, Vol. 36, 2003, pp. 7-13. doi:10.1107/S0021889802022112

[18] L. J. Farrugia, "ORTEP-3 for Windows: A Version of ORTEP-III with a Graphical User Interface (GUI)," Journal of Applied Crystallography, Vol. 30, 1997, p. 565. doi:10.1107/S0021889897003117

[19] H. M. Irving and R. J. P. Williams, "The Stability of Transition Metal Complexes," Journal of the Chemical Society, 1953, pp. 3192-3210. doi:10.1039/jr9530003192

[20] D. S. Flett, "Cobalt-Nickel Separation in Hydrometallurgy: A Review," Chemistry for Sustainable Develop- 
ment, Vol. 12, 2004, pp. 81-91.

[21] L. Alderighi, P. Gans, A. Ienco, D. Peters, A. Sabatini and A. Vacca, "Hyperquad Simulation and Speciation (HySS): A Utility Program for the Investigation of Equilibria Involving Soluble and Partially Soluble Species," Coordination Chemistry Reviews, Vol. 184, No. 1, 1999, pp. 311-318. doi:10.1016/S0010-8545(98)00260-4

[22] M. F. Perutz, "The Role of Aromatic Rings as HydrogenBond Acceptors in Molecular Recognition," Philosophical Transactions: Physical Sciences and Engineering, Vol. 345, No. 1674, 1993, pp. 105-112. doi:10.1098/rsta.1993.0122

[23] W. J. Geary, "The Use of Conductivity Measurements in Organic Solvents for the Characterisation of Coordination Compounds," Coordination Chemistry Reviews, Vol. 7, No. 1, 1971, pp. 81-122.

[24] T. J. Lane, I. Nakagawa, J. L. Walker and A. J. Kandathil, "Infrared Investigation of Certain Imidazole Derivatives and Their Metal Chelates," Inorganic Chemistry, Vol. 1, No. 2, 1962, pp. 267-276. doi:10.1021/ic50002a014

[25] J. Reedijk, "Pyrazoles and Imidazoles as Ligands. Part VI. Coordination Compounds of Metal(II) Perchlorates, Tetrafluoroborates and Nitrates Containing the Ligand $\mathrm{N}$ n-Butylimidazole," Journal of Inorganic and Nuclear Chemistry, Vol. 33, No. 1, 1971, pp. 179-188. doi:10.1016/0022-1902(71)80020-9

[26] E. S. Raper and J. L. Brooks, "Complexes of 1-Methylimidazoline-2-thione with $\mathrm{Co}(\mathrm{II})$ and $\mathrm{Zn}$ (II) Halides and Perchlorates," Journal of Inorganic and Nuclear Chemistry, Vol. 39, No. 12, 1977, pp. 2163-2166. doi:10.1016/0022-1902(77)80387-4

[27] Z. Nakamoto, "Infrared and Raman Spectra of Inorganic and Coordination Compounds," 3rd Edition, John Wiley and Sons, New York, 1978, p. 239.

[28] A. B. P. Lever, "Inorganic Electronic Spectroscopy," 2nd Edition, Elsevier, New York, 1984, pp. 554-557.

[29] H. P. Berends and D. W. Stephan, "Copper(I) and Copper(II) Complexes of Biologically Relevant Tridentate Ligands," Inorganica Chimica Acta, Vol. 93, No. 4, 1984, pp. 173-178. doi:10.1016/S0020-1693(00)88159-1

[30] J.-Y. Xu, W. Gu, L. Li, S.-P. Yan, P. Cheng, D.-Z. Liao and Z.-H. Jiang, "Synthesis and Crystal Structure of Nickel Complex of $N, N$-Bis(benzimidazol-2-yl-methyl)amine," Journal of Molecular Structure, Vol. 644, No. 1-3, 2003, pp. 23-27. doi:10.1016/S0022-2860(02)00281-8

[31] P. Thangarasu, S. Bernès and C. Durán de Bazúa, "Bis [bis(benzimidazol-2-ylmethyl-N ${ }^{3}$ )amine- $N$ ]nickel(II) Dichloride", Acta Crystallographica Section C-Crystal Structure Communications, Vol. 53, No. 11, 1997, pp. 1607 1609. doi:10.1107/S0108270197006513 